\title{
Soil applications of two neonicotinoid insecticides to control mealybugs (Pseudococcidae) in vineyards
}

\author{
P.L. Lo and J.T.S. Walker \\ The New Zealand Institute for Plant \& Food Research Limited, Private Bag 1401, \\ Havelock North 4157, New Zealand \\ Corresponding author: Peter.Lo@plantandfood.co.nz
}

\begin{abstract}
Grapevine leafroll-associated Virus 3 debilitates grapevines, reducing yields and juice quality, and eventually makes vineyards uneconomic. Mealybugs (Pseudococcus spp.) are the key insect pests of grapes in New Zealand because they are the principal vectors of this virus. Until recently, all insecticides registered for their control depended on direct contact, but mealybugs live in hard-to-treat parts of vines. This research tested the efficacy of two neonicotinoid insecticides, imidacloprid and SCAL 5085, that have translaminar and systemic activity. Two field trials were conducted on commercial vineyards with the insecticides applied as soil drenches. In the first trial, imidacloprid applied at $0.525 \mathrm{~g}$ ai/vine reduced mealybug abundance by $>99 \%$ compared with untreated vines, and autumn and spring applications were equally effective. Half this rate was less effective, although drenching in autumn was better than in spring. In the second trial, treatments were applied in winter, and SCAL 5085 at $0.263 \mathrm{~g}$ ai/vine provided equivalent control to imidacloprid at $0.525 \mathrm{~g}$ ai/vine.
\end{abstract}

Keywords neonicotinoid, mealybug, Pseudococcus, grape, soil application.

\section{INTRODUCTION}

Grapevine leafroll disease is one of the most serious issues facing vineyards in New Zealand. It is caused by a complex of viruses, the predominant one being Grapevine leafroll associated Virus 3 (Bell et al. 2009). Over time, this virus debilitates vines, reducing grape yield and juice quality to such an extent, particularly in red varieties, that whole blocks have to be removed (rogued), making some vineyards uneconomic. Once present in a vineyard the virus can, if left unchecked, spread rapidly so that within a few years the majority of vines are infected.

Mealybugs (Pseudococcidae) are the key insect pests of grapes in New Zealand because they are the principal vector of grapevine leafroll virus (Petersen \& Charles 1997; Golino et al. 2002). Virus-infected mealybugs can spread the disease from vine to vine by walking, or more randomly over greater distances through aerial dispersal of the crawler stage, contaminated machinery and possibly on windblown leaves. The key species in both the North and South Islands are citrophilus mealybug (Pseudococcus calceolariae) and longtailed mealybug ( $P$. longispinus) (Charles et al. 2010).

Mealybugs live in 'hard-to-treat' parts of grapevines such as the underside of leaves, in crevices, inside bunches, under bark and on roots. 
Until recently, insecticides registered for their control on grapes in New Zealand all depended on direct contact for toxicity. These products include the broad spectrum organophosphates and carbamate (prothiofos, chlorpyrifos and methomyl), as well as the selective insect growth regulator buprofezin. However, full coverage of the various mealybug habitats is difficult to achieve.

In 2010 another insecticide, imidacloprid, was registered for use on grapes in New Zealand. Imidacloprid belongs to the neonicotinoid group of insecticides, which act on the insect central nervous system, causing paralysis and death. Neonicotinoids are effective against sucking insects such as aphids, whiteflies, mealybugs and thrips, and also some chewing insects (Elbert \& Nauen 2004). Their physical and chemical properties make them useful for a wide range of application techniques, including foliar, soil drench, stem application, drip irrigation and seed treatment (Elbert et al. 2008). An important attribute of neonicotinoid insecticides is their translaminar and systemic activity. Systemic insecticides can be particularly effective against cryptic sucking pests like mealybugs, because they can potentially reach a much greater proportion of the population than foliar-applied sprays.

A crucial part of the strategy to eliminate grapevine leafroll disease from vineyards and ultimately whole districts is to manage mealybug populations at very low levels during the elimination phase. Previous research to improve the effectiveness of direct-contact insecticides (Lo et al. 2009) has been conducted, but this only addressed the problem of mealybugs living above ground. Pseudococcus calceolariae (but not $P$. longispinus) also lives on roots and when vines are rogued, a large proportion of the roots remain in situ unless the land is thoroughly cultivated. These remnant roots can continue to support mealybug activity and retain grapevine leafroll virus for up to 4 years after the vine is removed (Bell et al. 2009), thereby acting as reservoirs of virus. There have been cases where vineyard managers replanted blocks immediately and the new vines quickly became infected with grapevine leafroll virus. It is strongly suspected that mealybugs on remnant roots can relocate and transmit the virus to young vines, although this has not been proven.

Imidacloprid has previously been tested as a foliar spray both pre- and post-harvest (P.L. Lo, unpublished data) with promising results. The present paper reports on two trials that compared the efficacy of imidacloprid and another neonicotinoid (SCAL 5085) against P. caleolariae when applied directly to the soil to be taken up by vine roots.

\section{METHODS}

\section{Trial 1}

To test efficacy of imidacloprid (Confidor ${ }^{\oplus}$ 350SC), the insecticide was applied at two rates in both autumn and spring, giving four treatments plus an untreated control. The application method followed that used to control mealybugs in South Africa (G. Pietersen, University of Pretoria, South Africa, pers. comm.), with imidacloprid mixed at the appropriate concentration to deliver $0.75 \mathrm{ml}(0.263 \mathrm{~g}$ of active ingredient $)$ or $1.5 \mathrm{ml}$ $(0.525 \mathrm{~g}$ ai) in $500 \mathrm{ml}$ of solution per vine. These rates were equivalent to approximately 600 and $1200 \mathrm{~g}$ ai/ha at a row spacing of $2.4 \mathrm{~m}$ and $1.8 \mathrm{~m}$ between vines. The solution was poured around the base of each vine and allowed to soak in before being watered in with 2 litres of water per vine. Each plot comprised a single bay containing five Cabernet Sauvignon vines in a randomised block design with six replicates. The autumn application was made on 6 May 2008, and the spring treatments were applied on 16 September 2008. On 25 March 2009, 25 leaves were picked at random from around the bunch zone and 15 bunches were randomly sampled per plot, taken to the laboratory and examined for insects.

Imidacloprid residues were tested in grape bunches from five sites: the trial block plus four others (varieties: Chardonnay $\times 2$, Pinot Noir, Merlot). In the four additional sites non-replicated plots were drenched as above with the same two rates of imidacloprid on 16 September 2008. A sample of bunches weighing approximately $1.5 \mathrm{~kg}$ was collected from each of the two spring treatments at each of the five blocks 24 weeks later 
on 5 March 2009. Samples were kept frozen until being sent to Hill Laboratories Ltd, Hamilton, for residue analysis. The limit of detection was $0.010 \mathrm{mg} / \mathrm{kg}$ (i.e. 1 part $/ 10^{8}$ ).

\section{Trial 2}

Three treatments were applied as a soil drench on 23 July 2009 using the same method as in trial 1. Imidacloprid (Confidor 350SC) was applied at $0.75 \mathrm{ml}(0.263 \mathrm{~g}$ ai $)$ and $1.5 \mathrm{ml}(0.525 \mathrm{~g}$ ai $)$ of product per vine, while SCAL 5085 (200SC) was applied at $1.3 \mathrm{ml}$ of product $(0.263 \mathrm{~g}$ ai $)$ per vine. There was an untreated control.

The trial was conducted within a commercial vineyard on two blocks of Cabernet Sauvignon and Chardonnay vines. Each plot comprised three adjacent vines and was separated from neighbouring plots by one untreated vine. Treatments were arranged in a randomised block design with eight replicates per variety. On 1 April 2010, 25 leaves per plot were randomly picked as in trial 1 from both blocks and the number of mealybugs on each leaf was counted in the laboratory.

\section{Assessment and data analysis}

The mean numbers of mealybugs per leaf or bunch and percentage infestations were calculated for each plot. The means were transformed $(\log x+1)$ and percentages by an arcsine transformation to standardise the variances before being analysed by a one-way ANOVA. A Fisher's protected least significant difference test $(\propto=0.05)$ was performed to distinguish significant treatment differences. Untransformed means are presented in the graphs.

\section{RESULTS}

\section{Trial 1}

All insecticide treatments significantly reduced $P$. calceolariae infestations on leaves and bunches at harvest (Figure 1, P< 0.001). The best treatments were the $0.525 \mathrm{~g}$ ai/vine applications in autumn and spring, which were equally effective. Vines treated with this rate had more than 99\% fewer mealybugs on both leaves and bunches than untreated vines. The proportions of infested leaves and bunches were reduced by $82 \%$ to $91 \%$ for treated vines compared with the control plants. For vines treated with $0.263 \mathrm{~g}$ ai of imidacloprid, the autumn timing reduced infestations significantly more than the spring application. The former reduced numbers of mealybugs on leaves and bunches by $95 \%$ and $94 \%$ respectively. Comparative figures for the spring application were about $80 \%$ reduction in mealybug numbers.

All five samples from vines treated with $0.263 \mathrm{~g}$ ai of imidacloprid had no detectable residues 24 weeks after application. Four of the five samples dosed with the $0.525 \mathrm{~g}$ ai rate also returned negative results, but the remaining sample (Chardonnay) had a residue level of $0.018 \mathrm{mg} / \mathrm{kg}$, which was just above the limit of detection.

\section{Trial 2}

The Cabernet Sauvignon block had a 10-fold greater number of $P$. calceolariae on untreated vines and the incidence was five times higher than in the Chardonnay block (Figure 2). In the Cabernet Sauvignon block, all insecticide treatments reduced the numbers of mealybugs per leaf or bunch compared with the untreated control $(\mathrm{P}<0.001)$, and there was no statistical difference between the insecticide treatments. The high rate of imidacloprid reduced numbers of mealybugs by $96 \%$ compared with $46 \%$ in the low rate. Vines treated with SCAL 5085 had 99\% fewer P. calceolariae than untreated vines. The SCAL 5085 treatment provided equivalent control to that of the high rate of imidacloprid, which had twice as much active ingredient. The three insecticide treatments essentially reduced mealybug infestations by similar amounts in the Chardonnay block. Compared with untreated vines, numbers of mealybug were reduced by $83 \%(\mathrm{P}=0.011)$ and the incidence by $63-79 \%$ $(\mathrm{P}=0.043)$.

\section{DISCUSSION}

In both trials, the soil drench applications of imidacloprid were highly effective at reducing P. calceolariae populations, particularly when applied at $0.525 \mathrm{~g}$ ai/vine. In trial 1 , the 

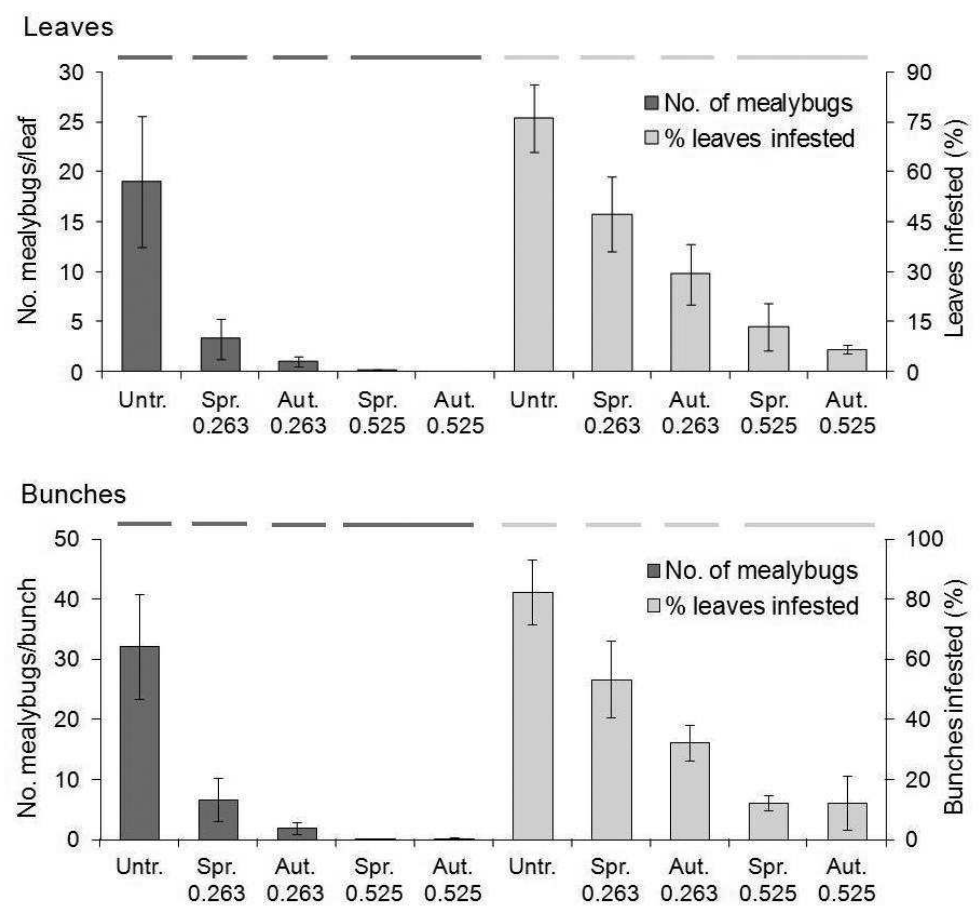

Figure 1 Mean $( \pm$ SEM) number of Pseudococcus calceolariae per grapevine leaf or bunch, and percentage of leaves or bunches infested for two rates ( 0.263 or $0.525 \mathrm{~g}$ ai per vine) of imidacloprid applied at two times of year (Spr. = spring; Aut. = autumn) as a soil drench. Treatments with a different line above the columns were significantly different $(\mathrm{P} \leq 0.05)$ for either the number of mealybugs present or the percentage infested. Untr. = control.

insecticide rate was more important than the time of application. At the lower rate, autumn timing was more effective than a spring application. It had been thought that the product might be most effective when vines were growing actively (i.e. spring), but it may be that the length of time in the vine was more important. Results from South Africa support the present finding that an autumn soil drench was more effective than a spring application (G. Pietersen, University of Pretoria, South Africa, pers. comm.). Applying imidacloprid in winter (trial 2) was also highly effective. The SCAL 5085 treatment was extremely effective, almost eliminating mealybugs from the heavily infested Cabernet Sauvignon. Its performance was equivalent to that of the higher rate of imidacloprid.
Imidacloprid applied in a similar way was effective against another mealybug species, $P$. ficus, on grapevines in South Africa. There it gave an equivalent degree of control to that from two prothiofos sprays (Elbert \& Nauen 2004). In California, mealybugs were also controlled when imidacloprid was applied through irrigation lines or into furrows (Daane et al. 2006). A further benefit of soil drenching is that the insecticide is transported to the pest without harming predators and parasitoids, and can be applied before they are active.

The current registration for imidacloprid restricts its use to non-cropping vines. Under this condition, it could be used to kill mealybugs on the roots of mature vines that are about to be removed, or to protect young plants that have replaced virus-infected vines that have been 

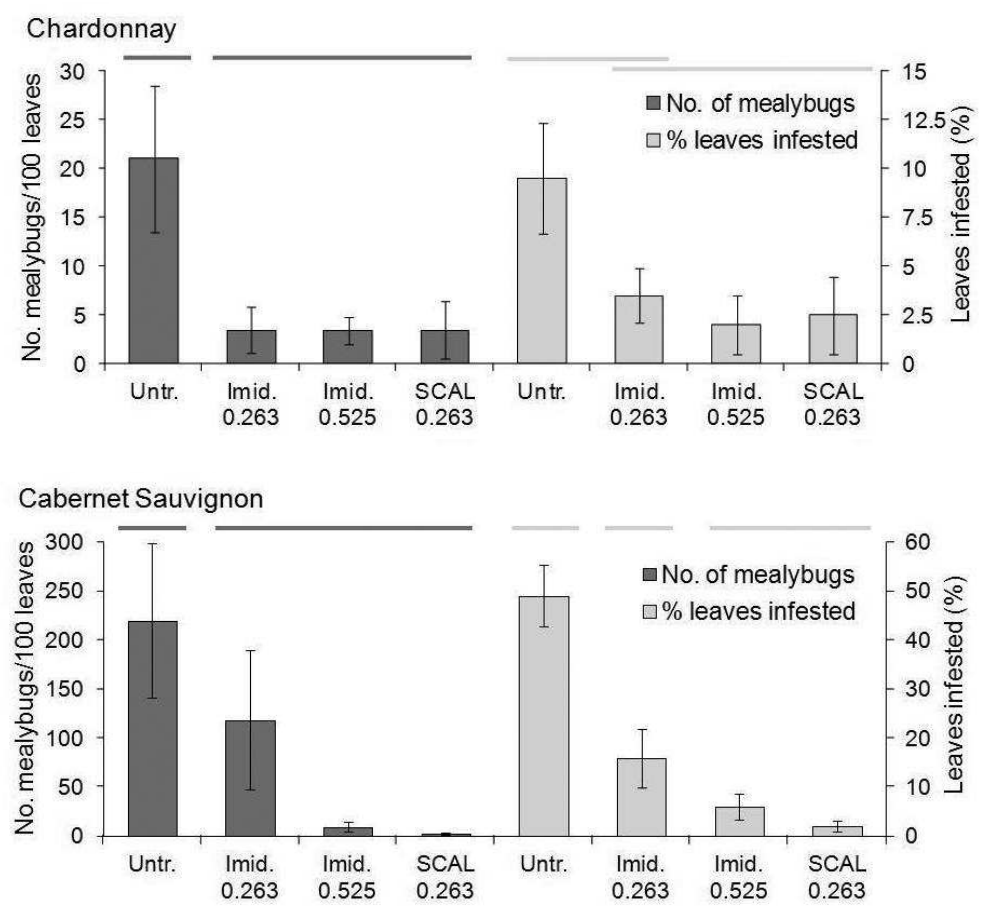

Figure 2 Mean $( \pm$ SEM) number of Pseudococcus calceolariae and percentage of leaves infested at harvest 2010 on two grape blocks treated with soil drench applications of two insecticides (Imid. = Confidor 350SC; SCAL = SCAL 5085 200SC) applied at 0.263, 0.525 or $0.26 \mathrm{~g}$ ai per vine in July 2009. Treatments with a different line above the columns were significantly different $(P \leq 0.05)$ for either the number of mealybugs present or the percentage infested. Untr. = control.

rogued. It is vital that young vines being planted into land that previously had virus-infected vines are given long-term protection from mealybug infestation, and soil drenching in this situation could be very useful in reducing the incidence of re-infection. Soil drench applications of imidacloprid are envisaged as forming part of a broader virus elimination strategy, which would include rouging individual diseased vines.

Imidacloprid soil treatments have good residual activity and can potentially protect vines for 2 years. However, this long-term suppression of mealybugs must be counter-balanced against the aim of New Zealand Winegrowers to have no detectable pesticide residues in crops at harvest. Because a residue was found in one of the springapplied samples, it is likely that soil drenching of imidacloprid for grape-bearing vines will be restricted to applications in autumn or early winter. The residue decay profile of SCAL 5085 has yet to be determined.

\section{CONCLUSIONS}

All the currently available insecticides against mealybugs, except imidacloprid, are contact products that rely on good spray coverage to have a high degree of efficacy. However, the physical nature of vines, with their multi-layered bark and dense canopies, means that sprayers can struggle to achieve the necessary coverage required for effective control.

Systemic insecticides such as neonicotinoids can provide a solution to the quandary of managing a cryptic pest with contact insecticides. These trials demonstrated the excellent efficacy that can be achieved by soil drenching. 
Imidacloprid, particularly at $0.525 \mathrm{~g}$ ai per plant, provided excellent control of $P$. calceolariae on mature vines, and SCAL 5085 applied at $0.263 \mathrm{~g}$ ai per vine was equally effective. Further research is required to establish the length of protection afforded to young plants.

\section{ACKNOWLEDGEMENTS}

This research was funded by New Zealand Winegrowers and Nufarm New Zealand Limited. We thank Pernod Ricard and Delegat's Wine Estate for making vineyard sites available. Imidacloprid was supplied by Bayer CropScience. Lyn Cole, Terrance Makea, Nandita Sharma and Tara Taylor provided technical support.

\section{REFERENCES}

Bell VA, Bonfiglioli RGE, Walker JTS, Lo PL, Mackay JF, McGregor SE 2009. Grapevine leafroll associated Virus 3 persistence in Vitis vinifera remnant roots. Journal of Plant Pathology 91: 515-521.

Charles JG, Bell VA, Lo PL, Cole LM, Chhagan A 2010. Mealybugs (Hemiptera: Pseudococcidae) and their natural enemies in New Zealand vineyards from 1993-2009. New Zealand Entomologist 33: 84-91.
Daane KM, Bentley WJ, Walton VM, MalakarKuenen R, Millar JG, Ingels CA, Weber EA, Gispert C 2006. New controls investigated for vine mealybug. California Agriculture 60: 31-38.

Elbert A, Haas M, Springer B, Thielert W, Nauen $\mathrm{R} 2$ 2008. Applied aspects of neonicotinoid uses in crop protection. Pest Management Science 64: 1099-1105.

Elbert A, Nauen R 2004. New applications for neonicotinoid insecticides using imidacloprid as an example. In: Horowitz AR, Ishaaya I ed. Insect pest management: field and protected crops. Springer-Verlag, Berlin. Pp. 29-44.

Golino DA, Sim ST, Gill R, Rowhani A 2002. California mealybugs can spread grapevine leafroll disease. California Agriculture 56: 196-201.

Lo PL, Bell VA, Walker JTS 2009. Maximising the effectiveness of insecticides to control mealybugs in vineyards. New Zealand Plant Protection 62: 296-301.

Petersen CL, Charles JG 1997. Transmission of grapevine leafroll-associated closteroviruses by Pseudococcus longispinus and P. calceolariae. Plant Pathology 46: 509-515. 